\title{
Predicting BRICS Stock Returns Using ARFIMA Models
}

\author{
Goodness C. Aye $e^{a}$, Mehmet Balcilar ${ }^{b}$, Rangan Gupta ${ }^{c}$, Nicholas Kilimani ${ }^{a}$, \\ Amandine Nakumuryango ${ }^{a}$, Siobhan Redford ${ }^{a}$
}

\begin{abstract}
This paper examines the existence of long memory in daily stock market returns from Brazil, Russia, India, China, and South Africa (BRICS) countries and also attempts to shed light on the efficacy of Autoregressive Fractionally Integrated Moving Average (ARFIMA) models in predicting stock returns. We present evidence which suggests that ARFIMA models estimated using a variety of estimation procedures yield better forecasting results than the non-ARFIMA (AR, MA, ARMA and GARCH) models with regard to prediction of stock returns. These findings hold consistently the different countries whose economies differ in size, nature and sophistication.
\end{abstract}

JEL classification: $C 15, C 22, C 53$

Keywords: fractional integration, long-memory, stock returns, long-horizon prediction, ARFIMA, BRICS

\section{Introduction}

The potential presence of long memory in financial time series has been one of the popular research topics in finance in recent years. This is particularly so since the seminal contributions of Clive W.J. Granger (Granger, 1980; Granger and Joyeux, 1980). Theoretical and empirical evidence in the field of finance regarding the presence of long-memory in stock returns in particular is varied. ${ }^{1}$ Consequently, modeling long-memory properties in stock market returns and volatility has stimulated a lot of research interest in recent years. This is not surprising given the important implications long memory has for financial

\footnotetext{
${ }^{a}$ Department of Economics, University of Pretoria, Pretoria, 0002, South Africa.

${ }^{b}$ Department of Economics, Eastern Mediterranean University, Famagusta, Turkish Republic of Northern Cyprus, via Mersin 10, Turkey.

${ }^{\mathrm{c}}$ Corresponding author. Department of Economics, University of Pretoria, Pretoria, 0002, South Africa,

Email: rangan.gupta@up.ac.za.

${ }^{a}$ Department of Economics, University of Pretoria, Pretoria, South Africa.

${ }^{a}$ Department of Economics, University of Pretoria, Pretoria, South Africa.

${ }^{a}$ Department of Economics, University of Pretoria, Pretoria, South Africa.

${ }^{1}$ See the literature review section for details.
} 
markets. A long memory process is a process where a past event has a decaying effect on future events. The presence of long-memory in stock returns and volatility implies that there exists a dependency between distant observations. From a statistical perspective, long-memory in these series is associated with a high autocorrelation function, which decays hyperbolically and eventually dies out. Conversely, if correlations between distant observations become negligible, the series is said to exhibit short-memory and possesses exponentially decaying summable correlations. Hence, the autocorrelation function for a stationary process shows an exponential decay and for a non-stationary process it shows an infinite persistence. Technically, a long memory process can be characterized by a fractionally integrated process (i.e. the degree of integration is less than one but greater than zero). Hence, the impacts of a shock persist over a long period of time (Kasman and Torun, 2007).

From an economic perspective, long-memory or long range dependence means that the information from "today" is not immediately absorbed by the prices in the market and investors react with delay to any such information. The existence of correlation between distant observations in the stock markets are of great interest to potential investors first taking into account their returns and second because they can be used for portfolio diversification and construction of trading strategies (Bardo $\bullet, 2008$ ). The major economic ramification for the presence of long-memory is the contradiction of the weak-form of market efficiency of Fama (1970) which allows investors and portfolio managers to make predictions and to construct speculative strategies. The price of an asset determined in an efficient market is assumed to follow a martingale process in which the current price change is unaffected by its previous value. By implication, the process should have no memory at all. This implies the absence of exploitable excess profit opportunities. However, when return series exhibit long memory, it indicates that observed returns are not independent over time. If returns are not independent, past returns can help predict future returns, thereby violating the market efficiency hypothesis. Consequently, pricing financial assets with martingale methods may not be appropriate if the underlying continuous stochastic process exhibits long-memory. Thus, investigating this long-memory property is critical for derivative market players, risk managers and asset allocation decisions makers, whose interest is to try and accurately predict stock market movements. Hence, the establishment of robust models that serve this purpose becomes a major research issue and is also an objective of the current study.

The use of long-memory models in predicting stock returns as done by Diebold and Inoue (2001), Engle and Smith (1999), and Granger and Hyung (1999), has resulted in what has been termed "spurious long-memory". ${ }^{2}$ As pointed out by

\footnotetext{
${ }^{2}$ This implies finding long-memory in sample tests even where there is none.
} 
these studies, spurious long-memory arises in many contexts. For instance, due to the presence of stochastic structural breaks in linear and nonlinear models, in the context of regime switching models, and when forming models using variables that are simple non-linear transformations of underlying "shortmemory" variables. It can also arise if one relies on any of the standard shortmemory tests, even if the data generating process does not possess any of the aforementioned properties (Bhardwaj and Swanson, 2003, 2006). The existence of spurious long-memory feature in financial time series has been widely studied. The bulk of existing empirical work has largely focused on the developed financial markets, while less attention has been accorded to emerging securities markets. More importantly for this study, there is limited empirical evidence of the usefulness of long-memory models for predicting stock returns. Granger (1999) acknowledges the importance of outliers, breaks, and undesirable distributional properties in the context of long-memory models, and concludes that there is the likelihood of $\mathrm{I}(\mathrm{d})$ processes falling into the "empty box" category. ${ }^{3}$ Bhardwaj and Swanson (2006) challenged this evidence by showing that ARFIMA models estimated using a variety of standard estimation procedures yield "approximations" to the true unknown underlying DGP. These in turn can sometimes provide significantly better out-of-sample predictions than simple linear non-ARFIMA models such MA, ARMA GARCH among others, when evaluated on the basis of point MSFE's as well as on the predictive accuracy tests and t-tests. In this study, we attempt to provide further evidence by assessing the performance of alternative models of predicting stock returns in the context of the emerging economies in general, and those of Brazil, Russia, India, China and South Africa (BRICS) in particular. ${ }^{4}$

Stock markets in emerging countries have become an important source for global portfolio diversification. However, there are challenges with regard to predicting stock returns of emerging stock market returns. Emerging markets are generally characterized by lower levels of liquidity and at the same time by a higher volatility than developed financial markets (Barkoulas et al., 2000; Kasman et al, 2009). High volatility in these markets is often marked by frequent and erratic changes, which are usually driven by various local events (such as political developments) rather than by the events of global importance (Bekaer and Harvey, 1997; Aggarwal et al., 1999). These different features may contribute to different dynamics underlying the returns and volatility, making these markets an interesting sphere of research. Understanding of the dynamic behavior of stock returns in these markets is crucial for portfolio managers, policy makers, and researchers. Therefore, the current paper attempts to add to the limited volume of literature on the usefulness of long-memory models in predicting stock

\footnotetext{
${ }^{3}$ By "empty box", Granger means ARFIMA models have stochastic properties that essentially do not mimic the properties of the data (Bhardwaj and Swanson, 2006).

${ }^{4}$ The only related studies for emerging markets are Kasman, et al. (2009) who focused on the Central and Eastern European (CEE) countries alone and Sivakumar and Mohandas (2009) who focused on India.
} 
returns by presenting ex ante forecasting evidence based on data sets from BRICS.

Specifically, we compare the ARFIMA and the non-ARFIMA (AR, MA, ARMA and GARCH) models with the view to providing evidence on the possible presence of long-term memory in the BRICS financial markets and testing which of these models yields robust results to this effect. We employ a variety of estimation methods and forecast evaluation techniques to realize these objectives. Evidence based on our analysis of the data sets from the BRICS suggests that ARFIMA models estimated using a variety of standard estimation procedures yield better approximations than non-ARFIMA models on the basis of point mean square forecast errors (MSFEs). This is in contrast to the findings of Granger (1999) but consistent with Bhardwaj and Swanson (2006).

\section{Literature Review}

A number of empirical studies on the presence of the long-memory in stock market returns have employed ARFIMA models in their analysis. However, the results of the empirical studies have been rather mixed. Starting with the pioneering work of Hurst (1951) and Greene and Fielitz (1977), Aydogan and Booth (1988) test for long-memory using the rescaled range. Fama and French (1988), Porterba and Summers (1988), Diebold and Rudebusch (1989, 1991a, b) all find no evidence of long-memory. Similarly, Lo (1991), using a modified rescaled range $(\mathrm{R} / \mathrm{S})$ statistic equally found no evidence of long-memory in a sample of US stock returns.

With respect to studies which have been carried out on emerging markets, evidence has been found supporting the presence of long-memory in some emerging markets. This is consistent with the lower levels of efficiency found in emerging markets. Assaf and Cavalcante (2005), Bellalah et al., (2005), Kilic (2004), and Wright (2002) apply a FIGARCH model to determine long-run dependency in the volatility of five emerging markets of Egypt, Brazil, Kuwait, Tunisia, Turkey and United States. In all cases the FIGARCH estimations yield a significant long-memory parameter, confirming the presence of long-memory in the volatility of these markets. However, no evidence of long-memory is found for the case of Vougas (2004) who finds weak evidence in the Greek markets when employing an ARFIMA-GARCH model, estimated via maximum conditional likelihood.

On the otherhand, a study by Cavalcante and Assaf (2002) examined the Brazilian stock market and concluded that volatility in these markets is characterized by the presence of long-memory. They find weak evidence of the existence of long-memory in the returns series of this market. However, Cajueiro and Tabak (2005) were predisposed to conclude that the presence of long-memory 
in the time series from financial assets is a stylized fact. Examining a sample of individual shares listed on the Brazilian stock market they find that specific variables from the firms explain, at least partially, long-memory in this market.

$\mathrm{Tu}$, Wong and Chang (2008) using financial market data from Hong Kong, Singapore, Australia, Korea, Malaysia, Thailand, Philippines, Indonesia, China and Japan assess the performance of variance at risk $(\mathrm{VaR})$ models that take into account skewness in the process of innovations. They employ an APARCH model based on the skewed $t$-distribution. They find the performance of this model to be inadequate in all cases. Babikir et al., (2012) examined the relationship between structural breaks and GARCH models of stock returns volatility of South Africa. Using a GARCH(1,1), high level of persistence in the parameter estimates was noticed due to the presence of structural breaks in the unconditional variance of stock returns. They also found that the combination of forecasts from different benchmark and computing models that allow for breaks in volatility improved the accuracy of volatility forecasting.

Bonga-Bonga and Makakabule (2010) used a Smooth Transition Regression (STR) to model the South African stock returns. Their results showed asymmetric behaviour of South African stock returns in the stock market. The study also put forward that the STR outperforms the OLS and random walk models in an outof-sample forecast. On the other hand, Makhwiting and Sigauke (2011) studied results for modelling the daily returns of the Johannesburg Stock Exchange (JSE) where returns are characterized by an $\operatorname{ARMA}(0,1)$ process implying that shocks to the unconditional mean dissipate after just one period.

In Batra (2004) asymmetric GARCH (E-GARCH) models were used for estimation and concluded that the Indian stock returns had highly persistent volatilities for the period 1979-2003. Additionally, Maheshchandra (2012) applied ARFIMA and FIGARCH models to examine the presence of long-memory for Indian stock returns for the period 2008-2011. The results suggest that there was no long-memory when using ARFIMA model while there was strong evidence of the presence of long-memory when using ARMA-FIGARCH $(1, d, 1)$.

In their study of the Brazilian stock market, Carvalho et al., (2006) showed that Brazilian stock volatility is lognormal with GARCH models and that there was no presence of long-memory using daily data of stock returns for the period 20012003. For the case of China, Liu et al., (2009) used the GARCH-SGED model which yielded more precise volatility forecasts than those obtained using the GARCH-N model for stock markets when the Shangai and Shenzen indices were considered. After applying the co-integration term on the forecasting model, Yoo (2011) concluded that the BRICK (Brazil, Russia, India, China and Korea) stock markets were not conditioned on developed stock markets as many investors thought. 
Jefferis and thupayagale (2008) examine long memory in equity returns and volatility for stock markets in Botswana, South Africa and Zimbabwe using the ARFIMA-FIGARCH model in order to assess the efficiency of these markets in processing information. They could not establish a consistent result for the three countries. They find significant long memory in the equity returns of Botswana; while, in South Africa this result is not statistically different from zero. For Zimbabwe returns are characterised by an anti-persistent process. Furthermore, all the markets investigated provide evidence of long memory in volatility with the exception of Botswana.

Kasman et al. (2009) investigate the presence of long memory in eight Central and Eastern European (CEE) countries' stock market, using the ARFIMA, GPH, FIGARCH and HYGARCH models. The results of these models indicate strong evidence of long memory both in conditional mean and conditional variance. Moreover, the ARFIMA-FIGARCH model provides the better out-of-sample forecast for the sampled stock markets. Sivakumar and Mohandas (2009) investigate the forecasting ability of ARFIMA-FIGARCH model using Indian stock returns. The performance of this model is compared with traditional Box and Jenkins ARIMA models. Their results illustrate the need for hybrid modeling as ARFIMA-FIGARCH performed better than the traditional models.

From the literature surveyed, one can deduce the following: first there are several methods for determining the existence of long-memory in returns, among which are ARFIMA models. Second, research has yielded mixed results in the case of emerging markets. Third, there is a dearth of studies on predictive ability of ARFIMA models especially for the BRICS.Consequently, the current study is set out to compare the non-ARFIMA and ARFIMA models with the view to putting forward additional evidence on the possible presence of long-term memory in the BRICS financial markets and testing which of these models yields robust results to this effect.

\section{Methodology}

In this section, we present the ARFIMA processes and the estimation and testing techniques used to investigate the predictability of stock returns.

\subsection{ARFIMA: Long-memory estimation}

A typical Autoregressive Fractionally Integrated Moving Average (ARFIMA) process is given as:

$$
\gamma(L)(1-L)^{d} y_{t}=\Psi(L) \varepsilon_{t}
$$

where, $L$ is the lag operator and the standard difference operator $(1-L)$ of an ARIMA process is replaced with a fractional difference operator $(1-L)^{d}$, where $d$ denotes the degree of fractional integration or simply thefractional differencing 
parameter, $\varepsilon_{t}$ is independently and identically distributed and the process is covariance stationary for $-0.5<d<0.5$; with mean reversion when $d<1$. This model is a generalisation of the fractional white-noise process as described in Granger (1980), Granger and Joyeux (1980), and Hosking (1981), where, for the purpose of analyzing the properties of the process, $\Psi(L)$ is set equal to unity. ${ }^{5}$ Given that many time series exhibit gradually decaying autocorrelations, the merits of using ARFIMA models with hyperbolic autocorrelation decay patterns in financial time series modeling are many. The vital role of the hyperbolic decay property can be easily be illustrated by noting that

$$
\begin{aligned}
(1-L)^{d}= & \sum_{j=0}^{\infty}(-1)^{j}\left(\begin{array}{l}
d \\
j
\end{array}\right)(L)^{j}=1-d L+\frac{d(d-1)}{2 !} L^{2}-\frac{d(d-1)(d-2)}{3 !} L^{3} \\
& +\ldots \ldots . . .=\sum_{j=0}^{\infty} b_{j}(d)
\end{aligned}
$$

for any $d>-1$. For $d>0$, the difference filter can also be developed further using a hyper geometric function as below:

$$
\begin{aligned}
& (1-L)^{d}=\Lambda(-d) \sum_{j=0}^{\infty} L^{k} \Lambda(j-d) / \Lambda(j+1)=F(-\mathrm{d}, 1,1, \mathrm{~L}), \\
& \text { where } \mathrm{F}(\mathrm{a}, \mathrm{b}, \mathrm{c}, \mathrm{z})=\Lambda(\mathrm{c}) /[\Lambda(\mathrm{a}) \Lambda(\mathrm{b})] \sum_{\mathrm{j}=0}^{\infty} \mathrm{z}^{\mathrm{j}} \Lambda(a+j) \Lambda(b+j) /[\Lambda(c+j) \Lambda(j+1)] .
\end{aligned}
$$

It is should be noted that the plausible reason for the emergence of a various range of techniques for estimation and testing of long-memory models is due to the lack of a full proof of good method of estimation. Many of the tests used for long-memory have been shown via finite sample experiments to perform quite poorly. Much of this evidence has been reported in the context of comparing one or two classes of estimators/tests, such as rescaled range (RR)-type estimators. In the current study, we employ a variety of estimators and tests. Specifically, we consider four widely used estimation methods and five different long-memory tests following Bhardwaj and Swanson (2006).

\subsection{Long-memory Model Estimation}

\subsubsection{GPH estimator}

The GPH estimation procedure is a two-step procedure, which begins with the estimation of $d$ and is based on the following log-periodogram regression: ${ }^{6}$

$$
\ln \left[I\left(\omega_{j}\right)\right]=\alpha_{0}+\alpha_{1} \ln \left[4 \sin ^{2}\left(\frac{\omega_{j}}{2}\right)\right]+v_{j,}
$$

where

\footnotetext{
${ }^{5}$ See Baillie (1996) for a series of surveys on the properties of the ARFIMA process.

${ }^{6}$ The regression model is usually estimated using ordinary least squares.
} 


$$
\omega_{j}=\frac{2 \pi j}{T}, \quad j=1,2, \ldots, m .
$$

The estimate of $d$ say $\hat{d}_{G P H}$ is $-\hat{\alpha}_{1}, \omega_{\mathrm{j}}$ represents the $m=\sqrt{T}$ frontier frequencies and $I\left(\omega_{j}\right)$ denotes the sample periodiogram which is defined as:

$$
I\left(\omega_{j}\right)=\frac{1}{2 \pi T}\left|\sum_{t=1}^{T} y_{t} e^{-\omega_{j} t}\right|^{2} .
$$

Note that the critical assumption for this estimator is that the spectrum of the $\operatorname{ARFIMA}(p, d, q)$ process is the same as that of an ARFIMA $(0, d, 0)$ process (the spectrum of the ARFIMA $(p, d, q)$ process in equation (1), under some regularity conditions, is given by $I\left(\omega_{j}\right)=z\left(\omega_{j}\right)\left(2 \sin \left(\frac{\omega_{j}}{2}\right)\right)^{-2 d}$, where $z\left(\omega_{j}\right)$ is the spectrum of an ARMA process). We use $m=\sqrt{T}$ as is done in Diebold and Rudebusch (1989), although the choice of $m$ when $\varepsilon_{t}$ is autocorrelated can significantly impact the empirical results (see Sowell, 1992 for discussion). Robinson (1995a) shows that $\left(\left(\pi^{2} / 24 m\right)^{-0.5}\left(\hat{d}_{G P H}-d\right) \rightarrow N(0,1)\right.$ for $-0.5<d<0.5$ and for $j=l, \ldots ., m$ in the equation (5) for $\omega$ above, where $l$ is analogous to the usual lag truncation parameter.

As is also the case with the next two estimators, the second step of the GPH estimation procedure involves fitting an ARMA model to the filtered data, given the estimate of $d$. Agiakloglou et al., (1992) show that the GPH estimator has substantial finite sample bias, and is inefficient when $\varepsilon_{t}$ is a persistent AR or MA process. Previous studies have assumed normality of the filtered data in order to use standard estimation and inference procedures in the analysis of the final ARFIMA model (see e.g. Diebold and Rudebusch, 1989, 1991a). Many versions of this estimator have continued to be widely used in the empirical studies. ${ }^{7}$

\subsubsection{WHI estimator}

Another semi-parametric estimator is the Whittle estimator which is commonly used to estimate $d$. The most robust of these is the one suggested by Künsch (1987) and modified by Robinson (1995b). It is another periodogram-based estimator, and the crucial assumption is that for fractionally integrated series, the autocorrelation $(\rho)$ at lag $l$ is proportional to $l^{2 d-1}$. This implies that the spectral density which is the Fourier transform of the autocovariance $\gamma$ is proportional to $\left(\omega_{j}\right)^{-2 d}$. The local Whittle estimator of $d$ say $\hat{d}_{W H I}$, is obtained by maximizing the local Whittle log likelihood at Fourier frequencies close to zero, given by:

\footnotetext{
${ }^{7}$ For a recent overview of frequency domain estimators, see Robinson (2003, Chapter 1).
} 


$$
\Lambda(d)=-\frac{1}{2 \pi m} \sum_{j=1}^{m} \frac{I\left(\omega_{j}\right)}{f\left(\omega_{j} ; d\right)}-\frac{1}{2 \pi m} \sum_{j=1}^{m} f\left(\omega_{j} ; d\right),
$$

where $f\left(\omega_{j} ; d\right)$ is the spectral density (which is proportional to $\left.\left(\omega_{j}\right)^{-2 d}\right)$. As frequencies close to zero are used, we require that $m \rightarrow \infty$ and $\frac{1}{m}+\frac{m}{T} \rightarrow 0$ as $T \rightarrow \infty$. Taqqu and Teverovsky (1997) show that $\hat{d}_{W H I}$ can be obtained by maximising the following function:

$$
\hat{\Lambda}(d)=\ln \left(\frac{1}{m} \sum_{j=1}^{m} \frac{I\left(\omega_{j}\right)}{\omega_{j}^{-2 d}}\right)-2 d \frac{1}{m} \sum_{j=1}^{m} \ln \left(\omega_{j}\right)
$$

Robinson (1995b) shows that for estimates of $d$ obtained in this way, $(4 m)^{0.5}\left(\hat{d}_{W H I}-d\right) \rightarrow N(0,1)$ for $-0.5<d<0.5$. Taqqu and Teverovsy (1997) study the robustness of standard, local, and aggregated Whittle estimators to non-normal innovations, and find that the local Whittle estimator performs well in finite samples. Similarly, Shimotsu and Phillips (2002) develop an exact local Whittle estimator that applies throughout the stationary and non-stationary regions of $d$; while Andrews and Sun (2002) develop an adaptive local polynomial Whittle estimator in order to address the slow rate of convergence and associated large finite sample bias associated with the local Whittle estimator. In this paper, we use the local Whittle estimator discussed in Taqqu and Teverovsky (1997).

\subsubsection{RR Estimator}

The rescaled range estimator was initially suggested as a test for long-term dependence in the time series. The statistic is calculated by dividing range with standard deviation. In particular, define:

$$
\hat{Q}_{T}=\frac{\hat{R}_{T}}{\hat{\sigma}_{T}}
$$

where $\hat{\sigma}_{T}$ is the maximum-likelihood variance estimator of $y_{t}$, and $\hat{R}_{T}=\max _{0<i \leq T} \sum_{t=1}^{i}\left(y_{t}-\bar{y}\right)-\min _{0<i \leq T} \sum_{t=1}^{i}\left(y_{t}-\bar{y}\right)$. The estimate of $d$, say $\hat{d}_{R R}$, is obtained using the result that $\operatorname{plim}_{T \rightarrow \infty}\left(T^{-d-0.5} \frac{\hat{R}_{T}}{\hat{\sigma}_{T}}\right)=\operatorname{constant}^{8}$ and

\footnotetext{
${ }^{8}$ See Hurst (1951) and Lo (1991).
} 


$$
\hat{d}_{R R}=\frac{\ln \left(\hat{Q}_{T}\right)}{\ln (T)}-0.5
$$

Lo (1991) shows that $T^{-0.5} \hat{Q}_{T}$ is asymptotically distributed as the range of a standard Brownian bridge. It is worth noting however that there are known limitations to testing for long-memory using $T^{-0.5} \hat{Q}_{T}$, specifically in the presence of data generated by a short-memory process combined with a long-memory component (see for example, Cheung 1993). In cognizance of this, Lo (1991) proposes the modified $R R$ test, whereby $\hat{\sigma}_{T}^{2}$ is replaced by a heteroskedastic and autocorrelation consistent variance estimator which is expressed as:

$$
\hat{\sigma}_{T}^{2}=\frac{1}{T} \sum_{t=1}^{T}\left(y_{t}-\bar{y}\right)^{2}+\frac{2}{T} \sum_{j=1}^{q} w_{j}(q)\left\{\sum_{t=j+1}^{T}\left(y_{t}-\bar{y}\right)\left(y_{t-j}-\bar{y}\right\},\right.
$$

where

$$
w_{j}(q)=1-\frac{j}{q+1}, \quad q<T .
$$

It is known from Phillips (1987) that $\hat{\sigma}_{T}^{2}$ is consistent when $q=0\left(T^{0.25}\right)$; at least in the context of unit root tests, although choosing $q$ in the current context can be a challenge. This statistic still weakly converges to the range of a Brownian bridge.

\subsubsection{AML Estimator}

The fourth estimator that we employ is the approximate maximum likelihood estimator of Beran (1995). For any ARFIMA model given by Equation (1) $d=m+\delta$ where $\delta \in(-0.5,0.5)$ and $m$ is an integer (which is taken as known) denoting the number of times the series must be differenced in order to attain stationarity, say:

$$
x_{t}=(1-L)^{m} y_{t} \text {. }
$$

To form the estimator, a value of $d$ is fixed, and an ARMA model is fitted to the filtered $x_{t}$ data yielding a sequence of residuals. This is repeated over a fine grid of $d=m+\delta$; and $\hat{d}_{A M L}$ is the value which minimizes the sum squared residuals. The choice of $m$ is critical, given that the method only yields asymptotically normal estimates of the parameters of the ARFIMA model if $\delta \in(-0.5,0.5)^{9}$.

In summary, three of the estimation methods described in the preceding paragraphs for ARFIMA models require first estimating $d$. Thereafter, an ARMA model is fitted to the filtered data by using maximum likelihood to estimate

\footnotetext{
${ }^{9}$ See Robinson (2003) for an extensive exposition of the AML estimator.
} 
parameters, and via the use of the Schwarz Information Criterion for lag selection.

\subsection{Short-memory tests}

Four of the five tests that we use when evaluating our time series are based on the above discussion, including the GPH, RR, MRR, and WHI tests, where the MRR is the modified RR test due to Lo (1991). Notice that of these, only the GPH and WHI tests are based directly upon examination of the $d$ estimator, while the $\mathrm{RR}$ and MRR tests do not involve first estimating $d$. The fifth test that we use is the non-parametric short-memory test of Leybourne et al. (2003). Their test is based on the rate of decay of the auto-covariance function. Specifically, the null hypothesis of the test is that the data are short-memory (i.e. $\sum_{j=0}^{\infty}\left|\gamma_{j}\right|<\infty$; where $\gamma_{j}$ is the auto-covariance of $y_{t}$ at $\operatorname{lag} j$ ) and the test is based on the notion that one can distinguish between short and long-memory via knowledge of the rate at which $\gamma_{j} \rightarrow 0$ as $j \rightarrow \infty$. The test statistics is given as:

$$
S_{k, T}=\frac{T^{0.5} \hat{\gamma}_{k T}}{\hat{\sigma}_{\infty}}
$$

where $\hat{\sigma}_{\infty}^{2}=\hat{\gamma}_{0}^{2}+2 \sum_{j=1}^{l_{T}} \hat{\gamma}_{j}^{2}, \hat{\gamma}_{j}=T^{-1} \sum_{t=j+1}^{T} y_{t} y_{t-j}, \quad y_{t}$ in this case is the demeaned series, and $k_{T}, l_{T}$ are chosen such that $k_{T}, t_{T} \rightarrow \infty$ and $\frac{k_{T}}{l_{T}} \rightarrow 0, k_{T}<l_{T}$. the values which we use as suggested by LHM, are $k_{T}=\frac{5.5 T^{0.5}}{\ln (T)}$ and $l_{T}=4\left(\frac{T}{100}\right)^{0.25}$. In this context, $S_{k T} \rightarrow N(0,1)$ under the null hypothesis.

\subsection{Predictive accuracy and testing}

Most often, the ultimate goal of an empirical investigation is the specification of predictive models, then a natural tool for testing for the presence of long-memory is the predictive accuracy test. In this case, if an ARFIMA model can be shown to yield predictions that are superior to those from a variety of alternative linear (and non-linear) models, then one has direct evidence of long-memory, at least in the sense that the long-memory model is the best available "approximation" to the true underlying DGP. Conversely, even if one finds evidence of long-memory via application of the tests discussed above, then there is little use specifying long-memory models if they do not out predict simpler alternatives. There is a rich recent literature on predictive accuracy testing, most of which draws in one way or another on Granger and Newbold (1986), where simple tests comparing mean-square forecast errors (MSFEs) of pairs of alternative models under 
assumptions of normality are outlined. Perhaps the most important of the predictive accuracy tests that have been developed over the last 20 years is the Diebold and Mariano (DM, 1995) test. The statistic is:

$$
\hat{d}_{p}=P^{-0.5} \frac{\sum_{t=R-h+1}^{T-1}\left(f\left(\hat{v}_{0, t+h}\right)-f\left(\hat{v}_{1, t+h}\right)\right.}{\hat{\sigma}_{p}},
$$

where $R$ denotes the estimation period, $P$ is the prediction period, $f$ is a generic loss function, $h \geq 1$ is the estimate horizon, $\hat{v}_{0, t+h}$ and $\hat{v}_{1, t+h}$ are $h$-step ahead prediction errors for the models $O$ and 1 (where model $O$ is assumed to be the ARFIMA model), constructed using estimators, and $\hat{\sigma}_{P}^{2}$ is defined as:

$$
\begin{aligned}
\hat{\sigma}_{P}^{2}= & \frac{1}{P} \sum_{t=R-h+1}^{T-1}\left(f\left(\hat{v}_{0, t+h}\right)-f\left(\hat{v}_{1, t+h}\right)\right)^{2} \\
& +\frac{2}{P} \sum_{j=1}^{l_{P}} w_{j} \sum_{t=R-h+1+j}^{T-1}\left(f\left(\hat{v}_{0, t+h}\right)-f\left(\hat{v}_{1, t+h}\right)\right)\left(f\left(\hat{v}_{0, t+h-j}-f\left(\hat{v}_{1, t+h-j}\right)\right),\right.
\end{aligned}
$$

where $w_{j}=1-\frac{j}{l_{P}+1}, l_{P}=0\left(P^{0.25)}\right.$. The hypotheses of interest are the following:

$H_{0}: E\left(f\left(\hat{v}_{0, t+h}\right)-f\left(v_{1, t+h}\right)\right)=0$

$H_{A}: E\left(f\left(\hat{v}_{0, t+h}\right)-f\left(v_{1, t+h}\right)\right) \neq 0$.

The DM test, when constructed as outlined above for non-nested models, has a standard normal limiting distribution under the null hypothesis. ${ }^{10}$ West (1996) shows that when the out-of-sample period grows at a rate not slower than the rate at which the estimation period grows (i.e. $\frac{P}{R} \rightarrow \pi$, with $0<\pi \leq \infty$ ), parameter estimation error generally affects the limiting distribution of the DM test in stationary contexts. On the other hand, if $\pi=0$ then the parameter estimation error has no effect. Additionally, Clark and McCracken (2001) point out the importance of addressing the issue of nestedness when applying DM and related tests. ${ }^{11}$ Although, the DM test does not have a normal limiting distribution under the null of non-causality when nested models are compared, the statistic can still

\footnotetext{
${ }^{10}$ We assume quadratic loss in our applications, so that $f\left(v_{0, t+h}\right)=v_{0, t+h}^{2}$; for example.

${ }^{11}$ Chao et al., (2001) address not only nestedness, by using a consistent specification testing approach to predictive accuracy testing, but also allow for misspecification amongst competing models; an important feature if one is to presume that all models are approximations, and hence all models may be (dynamically) misspecified. White (2000) further extends the Diebold and Mariano framework by allowing for the joint comparison of multiple models, while Corradi and Swanson (2005a,b,c) extend White (2000) to predictive density evaluation with parameter estimation error.
} 
be used as an important diagnostic in predictive accuracy analyses. Furthermore, the non-standard limit distribution is approximated by a standard normal in many contexts (see McCracken, 1999 for tabulated critical values). In this regard, we use critical values obtained from the $N(0,1)$ distribution when carrying out DM tests.

Note that McCracken (1999) and Clark and McCracken (2001) assume stationarity and correct specification under the null hypothesis, and that estimation is done using ordinary least squares. If we make the assumption of correct specification under the null, it implies that the ARFIMA model and the non-ARFIMA models are the same. Hence $d=0$; so that only the common ARMA components in the models remain, and therefore, the errors are short-memory.

We also evaluate forecasts from ARFIMA and Non-ARFIMA models using Clark and McCracken (2001) encompassing test which is designed for comparing nested models. The test statistic is given as:

$$
E N C-t=(P-1)^{0.5} \frac{\bar{c}}{\left(P^{-1} \sum_{t=R}^{T-1}\left(c_{t+h}-\bar{c}\right)^{0.5}\right.} \bar{c},
$$

where $c_{t+h}=\hat{v}_{0, t+h}\left(\hat{v}_{0, t+h}-\hat{v}_{1, t+h}\right)$ and $\bar{c}=P^{-1} \sum_{t=R}^{T-1} c_{t+1}$. The test has the same hypotheses as the DM test, except that the alternative is $H_{A}: E\left(f\left(\hat{v}_{0, t+h}\right)-f\left(v_{k, t+h}\right)\right)>0$. If $\pi=0$, the limiting distribution is $N(0,1)$ for $h=1$. The limiting distribution for $h>1$, is non-standard. However, as long as the Newey and West (1987)-type estimator (of the generic form given above for the DM test) is used when $h>1$, then the tabulated critical values are quite close to the $N(0,1)$ values and hence we use the standard normal distribution as a benchmark guide for all horizons. ${ }^{12}$

\subsection{Predictive model selection}

In this paper, forecasts are 1-step, 5-steps and 20-steps ahead, when daily stock market data are examined, corresponding to 1-day, 1-week and 1-month ahead predictions. Estimation is carried out as discussed above for ARFIMA models, and using maximum likelihood for non-ARFIMA models. More precisely, each sample of $\mathrm{T}$ observations is first split in half. The first-half of the sample is then used to produce 0:25T rolling (and recursive) predictions (the other 0:25T observations are used as the initial sample for model estimation) based on rolling (and recursively) estimated models (i.e. parameters are updated before each new prediction is constructed).

\footnotetext{
${ }^{12}$ See Clark and McCracken (2001) for an extended discussion.
} 
These predictions are then used to select a "best" ARFIMA and a "best" nonARFIMA model, based on point out-of-sample mean-square forecast error comparison. At this juncture, the specifications of the ARFIMA and non-ARFIMA models to be used in later predictive evaluation are fixed. Parameters in the models may be updated, however. In particular, recursive and rolling ex ante predictions of the observations in the second half of the sample are then constructed, with parameters in the ARFIMA and non-ARFIMA "best" models updated before each new forecast is constructed. Additionally, different models are constructed for each forecast horizon, as opposed to estimating a single model and iterating forward when constructing multiple step ahead forecasts. Reported $D M$ and encompassing $t$ tests are thus based on the second-half of the sample, and involve comparing only two models.

With regard to model selection, Inoue and Kilian (2003), suggest the use of the Schwarz Information Criterion (SIC) for choosing the best forecasting model, while Hansen et al., (2004) HLN propose a model confidence set approach to the same problem. It is worth noting that the BIC-based approach of Inoue and Kilian (2003) is not applicable under near stationarity and non-linearity, and is not consistent when non-nested models are being compared. Hansen et al., (2004) takes a different approach on the other hand, as they are concerned with narrowing down from a larger set of models to a smaller set that encompasses the best forecasting model. When their approach is used, for example, it is found that ARFIMA volatility models do not outperform simpler non-ARFIMA volatility models. In this study, we use SIC for model selection.

\section{Data and Empirical evidence}

The data have been sourced from the websites of the stock exchanges in each country considered. The data is the daily index representing a significant portion of the capitalisation of each stock exchange. From this daily stock returns were calculated. The data starts in September 1995 and terminates over the period of 30 July 2012 to 6 September 2012 for the different countries. For Brazil, the Ibovespa is used and represents more than 80 per cent of the number of trades and financial value traded, as well as representing over 70 per cent of the total market capitalisation of the stock exchange. Russia's All RTS index is used which comprises 50 preferred and common shares chosen according to capitalisation. The Bombay sensitive index has been chosen in the case of India which tracks 30 stocks and is weighted according to market capitalisation. China's Shanghai stock exchange A-share index is included; this index comprises stocks listed as A shares. Finally the FTSE/JSE All Share index is used to represent South Africa's stock returns; it comprises the top 99 per cent of eligible listed companies and is weighted according to market capitalisation.

The empirical estimation is based on the following models: 
$\operatorname{ARFIMA}(p, d, q): \gamma(L)(1-L)^{d} y_{t}=\beta+\Psi(L) \varepsilon_{t}$

where $d$ takes fractional values.

Random Walk with a Drift: $y_{t}=\beta+y_{t-1}+\varepsilon_{t}$

$A R(p): \gamma(L) y_{t}=\beta+\varepsilon_{t}$

$M A(q): y_{t}=\beta+\Psi(L) \varepsilon_{t}$

$\operatorname{ARMA}(p, q): \gamma(L) y_{t}=\beta+\Psi(L) \varepsilon_{t}$

$\operatorname{ARIMA}(p, d, q): \gamma(L)(1-L)^{d} y_{t}=\beta+\Psi(L) \varepsilon_{t}$, where $d$ can take integer values;

GARCH: $\gamma(L) y_{t}=\beta+\varepsilon_{t}$ where $\varepsilon_{t}=h_{t}^{0.5} v_{t}$ with

$$
\begin{aligned}
& E\left(\varepsilon_{t}^{2} \mid \xi_{t-1}\right)=h_{t}=\varpi+\beta_{1} \varepsilon_{t-1}^{2}+ \\
& \ldots+\beta_{q} \varepsilon_{t-q}^{2}+\beta_{1} h_{t-1}+\ldots .+\beta_{p} h_{t-p},
\end{aligned} \text { and where } \xi_{t-1} \text { is the usual filtration of }
$$

the data.

In these models, $\varepsilon_{t}$ is the disturbance term $\gamma(L)=1-\phi_{1} L-\phi_{2} L^{2}-\ldots-\phi_{p} L^{p}$, and $\Psi(L)=1-\theta_{1} L-\theta_{2} L^{2}-\ldots-\theta_{q} L^{q}$, where $L$ is the lag operator. All models (except ARFIMA models) are estimated using (quasi) maximum likelihood, with values of $p$ and $q$ chosen via use of the Schwarz Information Criterion (SIC), and integer values of $d$ in ARIMA models selected via application of the augmented DickeyFuller test at a 5\% level. Errors in the GARCH models are assumed to be normally distributed. ARFIMA models are estimated using the four estimation techniques discussed above (GPH, RR, WHI, and AML).

The results are presented in Table 1 with the number of observations used in each set of analysis included in brackets below the name of the relevant country. The analysis chooses the best ARFIMA and non-ARFIMA models given the data, these are reported in the third and fifth columns of Table 1. The GPH and AML estimators were most often chosen for the ARFIMA models, whilst the ARGARCH(1) and random walk models dominated the best non-ARFIMA models. The only exception in the case of the non-ARFIMA models was the 20-day ahead rolling model for South Africa where an AR-GARCH (10) was chosen, , thus having significantly more autoregressive terms than chosen for any other returns series. These results are ex-ante estimates as described earlier. The size of $d$ for Russia, India and China is frequently greater than 0.5, especially at horizons of 5- and 20-days ahead irrespective of the estimation scheme (i.e. rolling or recursive).This falls largely in line with results presented in Table 2 of Bhardwaj 
and Swanson (2006). The standard errors obtained from the re-estimation of $d$ for each forecast and reported in parenthesis in column four are relatively small. Additionally, all the forecasts for South Africa and Brazil fall below 0.5, and the rolling estimates are particularly low at less than 0.1 , implying the presence of covariance stationarity in this process.

The results of the $D M$ test, reported in the sixth column of Table 1 give the results of a test that compares the MSFE of the best ARFIMA model with the best non-ARFIMA model. Negative values of the $D M$ statistics indicate that the point MSFE associated with the ARFIMA model is lower than that for the NonAfrica model since the former is taken as model zero. The results for every country are negative, which offhand suggest that the MSFE for the ARFIMA models are consistently lower than the non-ARFIMA models, adding further support to the use of ARFIMA models for stock market return forecasting. Most of the test statistics are significant at all conventional levels ${ }^{13}$. These are the DM test statistics for India's 5-day ahead recursive and rolling forecasts and South Africa's 20-day ahead rolling forecast. Thus, other than the exceptional cases identified, according to the DM test the ARFIMA models are preferred. In terms of the forecast encompassing (ENC-t) test, which tests as to whether the nonARFIMA model is nested within the ARFIMA model, the findings suggest that there is little reason to reject the null hypothesis of nestedness in most cases. There are two exceptions where the null is not accepted (suggesting that the nonARFIMA is the more accurate forecasting model) and that is for the 5-day ahead rolling models for Brazil and the 20-day ahead models recursive models for South Africa. Thus, the results point to a great extent to the existence of a long-memory process in the absolute daily returns of the stock markets considered and that an ARFIMA model has a role to play in forecasting exercises for stock returns at the 1-, 5- and 20-day ahead horizons.

The final column compares the forecast errors of the ARFIMA and non-ARFIMA models. Thus, any figure greater than one suggests that the MSFE for the ARFIMA models is higher than for the non-ARFIMA models and vice versa. The results suggest that for all models at all horizons for all countries, that the best ARFIMA model produces a lower MSFE than the best non-ARFIMA model. This lends further support to the evidence that ARFIMA models are better predictors than the non-ARFIMA options.

\footnotetext{
${ }^{13}$ The normal distribution, $\mathrm{N}(0,1)$, has been used as a rough guide for significance in the case of the DM and ENC-t statistics.
} 
Table 1: Analysis of absolute returns for Brazil, Russia, India, China and South Africa

\begin{tabular}{|c|c|c|c|c|c|c|c|c|c|c|}
\hline & & $\begin{array}{l}\text { ARFIMA } \\
\text { model }\end{array}$ & $d$ & $\begin{array}{c}\text { (Std } \\
\text { error) }\end{array}$ & $\begin{array}{c}\text { Non-ARF IMA } \\
\text { model }\end{array}$ & $\begin{array}{l}\text { MSFE } \\
\text { ratio }\end{array}$ & DM & & ENC-t & \\
\hline \multirow{6}{*}{$\begin{array}{l}\text { Brazil } \\
(4173)\end{array}$} & 1-day ahead, recursive & $\operatorname{AML}(1,1)$ & 0.3770 & 0.0199 & $\operatorname{GARCH}(1,1)$ & 0.0192 & -2.4281 & ** & -1.5147 & \\
\hline & 5-day ahead, recursive & $\operatorname{AML}(1,1)$ & 0.3770 & 0.0199 & RW & 0.5692 & -7.4267 & $* * *$ & 0.7984 & \\
\hline & 20-day ahead, recursive & $\operatorname{AML}(1,1)$ & 0.3770 & 0.0199 & $\operatorname{GARCH}(1,1)$ & 0.0138 & -1.9397 & $*$ & -3.6880 & \\
\hline & 1-day ahead, rolling & $\operatorname{AML}(1,1)$ & -0.0053 & 0.2259 & $\operatorname{GARCH}(1,1)$ & 0.0198 & -2.4687 & $* *$ & 0.1836 & \\
\hline & 5-day ahead, rolling & $\operatorname{AML}(1,1)$ & -0.0053 & 0.2259 & RW & 0.5726 & -7.4583 & $* * *$ & 1.2997 & * \\
\hline & 20-day ahead, rolling & $\operatorname{AML}(1,1)$ & -0.0053 & 0.2259 & $\operatorname{GARCH}(1,1)$ & 0.0144 & -1.9793 & $* *$ & -0.4706 & \\
\hline \multirow{6}{*}{$\begin{array}{l}\text { Russia } \\
(4240)\end{array}$} & 1-day ahead, recursive & $\operatorname{AML}(2,1)$ & 0.1501 & 0.0203 & $\operatorname{GARCH}(1,1)$ & 0.0289 & -2.9199 & * & -1.8090 & \\
\hline & 5-day ahead, recursive & $\operatorname{GPH}(1,1)$ & 0.6629 & 0.0464 & $\operatorname{GARCH}(1,1)$ & 0.0194 & -2.3574 & $* *$ & -0.9369 & \\
\hline & 20-day ahead, recursive & GPH $(1,1)$ & 0.6629 & 0.0464 & $\operatorname{GARCH}(1,1)$ & 0.0215 & -2.4350 & $* *$ & -1.5285 & \\
\hline & 1-day ahead, rolling & GPH $(1,1)$ & 0.7364 & 0.0897 & $\operatorname{GARCH}(1,1)$ & 0.0300 & -2.9600 & $* * *$ & 0.2044 & \\
\hline & 5-day ahead, rolling & GPH $(1,1)$ & 0.7364 & 0.0897 & $\operatorname{GARCH}(1,1)$ & 0.0206 & -2.4194 & $* *$ & 0.1602 & \\
\hline & 20-day ahead, rolling & WHI $(1,1)$ & 0.6205 & 0.0192 & $\operatorname{GARCH}(1,1)$ & 0.0224 & -2.4824 & $* *$ & -0.9490 & \\
\hline \multirow{6}{*}{$\begin{array}{l}\text { In dia } \\
(4214)\end{array}$} & 1-day ahead, recursive & GPH $(1,1)$ & 0.5383 & 0.0392 & RW & 0.5456 & -7.0939 & $* * *$ & -1.7616 & \\
\hline & 5-day ahead, recursive & GPH $(1,1)$ & 0.5383 & 0.0392 & $\operatorname{GARCH}(1,1)$ & 0.0194 & -1.5157 & & -1.6006 & \\
\hline & 20-day ahead, recursive & GPH $(1,1)$ & 0.5383 & 0.0392 & RW & 0.5666 & -5.6930 & $* * *$ & 0.3456 & \\
\hline & 1-day ahead, rolling & GPH $(1,1)$ & 0.6371 & 0.0620 & $\operatorname{GARCH}(1,1)$ & 0.0258 & -1.9965 & $* *$ & -1.0815 & \\
\hline & 5-day ahead, rolling & $\operatorname{GPH}(1,1)$ & 0.6371 & 0.0620 & $\operatorname{GARCH}(1,1)$ & 0.0175 & -1.6148 & & -1.8913 & \\
\hline & 20-day ahead, rolling & $\operatorname{GPH}(1,1)$ & 0.6371 & 0.0620 & RW & 0.5701 & -5.6747 & $* * *$ & -0.0101 & \\
\hline \multirow{6}{*}{$\begin{array}{l}\text { China } \\
(4119)\end{array}$} & 1-day ahead, recursive & $\operatorname{AML}(0,3)$ & 0.2866 & 0.0217 & $\operatorname{GARCH}(1,1)$ & 0.0190 & -2.5017 & *** & -0.1928 & \\
\hline & 5-day ahead, recursive & WHI $(2,1)$ & 0.5333 & 0.0068 & RW & 0.5125 & -7.8821 & $* * *$ & -1.6206 & \\
\hline & 20-day ahead, recursive & $\operatorname{GPH}(2,1)$ & 0.5862 & 0.0468 & RW & 0.5458 & -8.0691 & $* * *$ & 0.8741 & \\
\hline & 1-day ahead, rolling & $\operatorname{AML}(0,3)$ & 0.3661 & 0.0217 & $\operatorname{GARCH}(1,1)$ & 0.0235 & -2.4255 & $* *$ & -1.1795 & \\
\hline & 5-day ahead, rolling & $\operatorname{GPH}(2,1)$ & 0.6288 & 0.0068 & $\operatorname{GARCH}(1,1)$ & 0.0155 & -1.9475 & * & -0.7882 & \\
\hline & 20-day ahead, rolling & WHI $(2,1)$ & 0.5655 & 0.0468 & RW & 0.5474 & -8.0705 & $* * *$ & 0.6950 & \\
\hline \multirow{6}{*}{$\begin{array}{l}\text { South Africa } \\
(4250)\end{array}$} & 1-day ahead, recursive & $\operatorname{AML}(4,1)$ & 0.2586 & 0.0563 & RW & 0.5119 & -7.0051 & $* * *$ & -3.5658 & \\
\hline & 5-day ahead, recursive & $\operatorname{AML}(4,1)$ & 0.2586 & 0.0563 & RW & 0.5712 & -9.4633 & $* * *$ & 1.0349 & \\
\hline & 20-day ahead, recursive & $\operatorname{AML}(4,1)$ & 0.2586 & 0.0563 & RW & 0.5650 & -6.6615 & $* * *$ & 1.5153 & \\
\hline & 1-day ahead, rolling & $\operatorname{AML}(4,1)$ & 0.0363 & 0.1399 & RW & 0.5067 & -6.9875 & $* * *$ & -1.5163 & \\
\hline & 5-day ahead, rolling & $\operatorname{AML}(4,1)$ & 0.0363 & 0.1399 & RW & 0.5692 & -9.4958 & $* * *$ & 1.0624 & \\
\hline & 20-day ahead, rolling & $\operatorname{AML}(4,1)$ & 0.0363 & 0.1399 & $\operatorname{GARCH}(1,1)$ & 0.0004 & -1.4076 & & -1.3305 & \\
\hline
\end{tabular}

represent significance of the test statistics at the 1,5 and 10 per cent levels respectively. These are based on the standard normal distribution. In the case of the DM statistic, a two-tailed test is conducted such that the critical values are 2.54, 1,96 and 1,65 respectively. The ENC-t test is a one-tailed test with critical values $2.33,1,65$ and 1.29 respectively. The MSFE ratio calculates the ratio between the MSFE for the ARFIMA model relative to the non-

\section{Conclusion}

This paper investigates the existence of long-memory processes in the absolute returns of indices for the Brazilian, Russian, Indian, Chinese and South African stock markets. In order to verify whether the true data generating process is better represented by ARFIMA or non-ARFIMA models, the study further compared the forecasts generated by these set of models. The best ARFIMA and best non-ARFIMA were first selected using part of the data. The remaining part 
of the data was used to produce ex-ante forecast from the best selected models using both recursive and rolling estimation schemes. We also employ a variety of estimators and forecast evaluation tests.

Our results provide strong evidence supporting the existence of long-memory in daily stock returns for the BRICS countries over different horizons. This is inconsistent with the weak-form market efficiency, implying that the BRICS stock index consists of the impact of news and shocks occurred in the recent past. Hence, speculative earnings could be gained via predicting stock prices. . The evidence also suggests that the ARFIMA models are better at forecasting daily stock market returns than the non-ARFIMA models. These findings hold true across all the BRICS countries whose economies differ in size, nature and sophistication, based on a number of tests. Thus, the usefulness of ARFIMA models, specifically for the purposes of forecasting at a number of horizons is further supported with the evidence presented in this paper. These findings would be helpful to the investors, financial managers, and regulators dealing with the BRICS stock markets. Understand the sources of long memory in the stock market could also assist the regulators in improving its efficiency. 


\section{References}

Aggarwal, R., Inclan, C. and Leal, R. (1999), "Volatility in Emerging Stock Markets", Journal of Financial and Quantitative Analysis 34(1): 33-55.

Agiakloglou, C., P., Newbold and M., Wohar (1992), Bias in an estimator of the fractional difference parameter. Journal of Time Series Analysis 14, 235-246.

Andrews, D.W.K., and Y., Sun (2002), Adaptive local Whittle estimation of longrange dependence. Working Paper, Yale University.

Assaf, A., and Cavalcante, J. (2005), Long range dependence in the returns and volatility of the Brazilian stock market. European Review of Economics and Finance, 4(2), 5-20.

Aydogan, K and G. G., Booth (1988), Are there long cycles in common stock returns? Southern Economic Journal, 55, 141-9.

Babikir, A., R. Gupta, C. Mwabutwa, E.O. Sekyere (2012), Structural breaks and GARCH models of stock return volatility: The Case of South Africa. Economic Modelling 29, 2435-2443.

Baillie, R.T., (1996), Long-memory processes and fractional integration in econometrics. Journal of Econometrics 73, 5-59.

Bardo •, S. (2008), Long Memory in Stock Returns: Research over Markets. PhD Thesis. Academy of Economic Studies - Bucharest.

Barkoulas, J.T., C.F., Baum and N., Travlos, (2000), Long-memory in the Greek stock market. Applied Financial Economics 10, 177-184.

Batra, A. (2004), Stock Return Volatility Patterns in India, Working Paper no. 124 [Online] Available:http://www.icrier.org/pdf/wp124.pdf.

Bekaert, Geert and Harvey, Campbell R., (1997), Emerging Equity Market Volatility. NBER Working Paper No. w5307.

Bellalah, M., Aloui, C., and Abaoub, E. (2005), Long-range Dependence in Daily Volatility on Tunisian stock market. International Journal of Business, 10(3), 191-216.

Beran, J., (1995), Maximum likelihood Estimation of the Differencing Parameter for Invertible Short and Long-memory Autoregressive Integrated Moving Average models. Journal of the Royal Statistical Society Series B 57, 659-672. 
Bhardwaj, G., and N.R., Swanson (2006), An empirical investigation of the usefulness of ARFIMA models for predicting macroeconomic and financial time series. Journal of Econometrics 131, 539-578.

Bhardwaj, G., and N.R., Swanson (2003), An empirical investigation of the usefulness of ARFIMA models for predicting macroeconomic and financial time series. Working Paper, Rutgers University.

Bonga-Bonga, L., M. Makakabule (2010), Modelling Stock Returns in the South African Stock Exchange: A Nonlinear Approach. European Journal of Economics, Finance and Administrative Sciences, 19, 168-177.

Cajueiro, D. O. and B. M. Tabak (2005), Possible causes of Long-range Dependence in the Brazilian stock market, Physica A: Statistical Mechanics and its Applications, 345, 635-645.

Carvalho, M. R. C., M. A. S. Freire, M. C. Medeiros, L. R. Souza (2006), Modeling and Forecasting the Volatility of Brazilian Asset Returns: A Realized Variance Approach. Revista Brasileira de Finanças 4:321-343.

Cavalcante, J., and A., Assaf (2002), Long Range Dependence in the Returns and Volatility of the Brazilian Stock Market Manuscript. Rio de Janeiro.

Chao, J.C., V., Corradi, V and N.R., Swanson (2001), An out of Sample Test for Granger Causality. Macroeconomic Dynamics 5, 598-620.

Cheung, Y.W (1993), Tests for fractional integration: a Monte Carlo investigation. Journal of Time Series Analysis 14, 331-345.

Clark, T.E., and M.W., McCracken (2001), Tests of equal forecast accuracy and encompassing for nested models. Journal of Econometrics 105, 85-110.

Corradi, V., and N.R., Swanson (2005a), Bootstrap procedures for Recursive Estimation Schemes with Applications to Forecast model selection. Working Paper, Rutgers University.

(2005b), Predictive Density and Conditional Interval Accuracy tests. Working Paper, Rutgers University. 
(2005c), Predictive density evaluation. In:

Elliott. G., Granger, C.W.J., Timmerman, A. (Eds.), Handbook of Economic Forecasting. Elsevier, Amsterdam, forthcoming.

Diebold, F., and A., Inoue (2001), Long-memory and regime switching. Journal of Econometrics 105, 131-159.

Diebold, F.X., R.S., Mariano (1995), Comparing predictive accuracy. Journal of Business and Economic Statistics 13, 253-263.

Diebold, F.X., and G.D., Rudebusch (1989), Long-memory and persistence in aggregate output. Journal of Monetary Economics 24, 189-209.

Diebold, F.X., G.D., Rudebusch, (1991a), Is consumption too smooth? Long Memory and the Deaton paradox. Review of Economics and Statistics 73, 1-9.

(1991b), On the power of the Dickey-Fuller test against Fractional Alternatives. Economics Letters 35, 155-160.

Engle, R.F., A.D, Smith (1999), Stochastic permanent breaks. Review of Economics and Statistics 81, 553-574.

Fama, E.F (1970), Efficient Capital Markets: A Review of Theory and Empirical Work" Journal of Finance, 25:383-417.

Fama, E. F., and K.R., French (1988) Permanent and temporary components in stock prices, Journal of Political Economy, 96, 246-73.

Granger, C.W.J (1980), Long-memory relationships and the aggregation of dynamic models. Journal of Econometrics 14, 227-238.

Granger, C.W.J., (1999), Aspects of research strategies for Time Series Analysis. Presentation to the Conference on New Developments in Time Series Economics, Yale University.

Granger, C., R., Joyeux (1980), An introduction to long-memory time series models and fractional differencing. Journal of Time Series Analysis 1, 15-39. 
Granger, C.W.J., P., Newbold (1986), Forecasting Economic Time Series. Academic Press, San Diego.

Granger, C.W.J and N., Hyung (1999), Occasional structural breaks and longmemory. Working Paper, University of California, San Diego.

Greene, M. and B., Fielitz (1977), Long term dependence in common stock returns, Journal of Financial Economics, 4, 339-49.

Hansen, P.R., A., Lunde and J.M., Nason (2004), Model Confidence sets for Forecasting Models. Working Paper, Brown University.

Harvey, D.I., S.J., Leybourne and P., Newbold (1997), Tests for forecast encompassing. Journal of Business and Economic Statistics 16, 254-259.

Hosking, J., (1981), Fractional differencing. Biometrica 68, 165-176.

Hurst, H.E., (1951), Long-term storage capacity of reservoirs. Transactions of the American Society of Civil Engineers 116, 770-799.

Inoue, A., L., Kilian (2003) On the selection of forecasting models. Working Paper, University of Michigan.

Jefferis, K. and Thupayagale, P. (2008), Long Memory in Southern African Stock Markets. South African Journal of Economics, 76 (3): 384-398.

Kasman, A. and Torun, E. (2007), Long Memory in the Turkish Stock Market Return and Volatility. Central Bank Review, 2: 13-27.

Kasman, A., S., Kasman and E., Torun (2009), Dual long-memory property in returns and volatility: Evidence from the CEE countries' stock markets. Emerging Markets Review 10:122-139.

Kilic, R., (2004), On the long memory properties of emerging capital markets: evidence from Istanbul stock exchange. Applied Financial Economics 14, 915922. 
Künsch, H.R., (1987), Statistical aspects of self-similar processes. In: Prohorov, Y., Sasanov, V.V. (Eds.), Proceedings of the First World Congress of the Bernoulli Society. VNU Science Press, Utrecht.

Leybourne, S., D., Harris and B., McCabe (2003), A robust test for short-memory. Working Paper, University of Nottingham.

Liu, H.C ., Y.H. Lee and M.C. Lee (2009),Forecasting China Stock Markets Volatility via GARCH Models Under Skewed-GED Distribution, Journal of Money, Investment and Banking, vol. 7, pp. 5-15.

Lo, A., (1991), Long-term memory in stock market prices. Econometrica 59, 1279-1313. McCracken, M.W., Asymptotics for out of sample tests of causality. Working Paper, Louisiana State University.

Maheshchandra, J.P. (2012), Long-memory Property in Return and Volatility: Evidence from the Indian Stock Markets. Asian Journal of Finance \& Accounting

Makhwiting, M.R., M. Lesaoana and C. Sigauke (2012), Modelling volatility and financial market risk of shares on the Johannesburg stock exchange. African Journal of Business Management Vol.6 (27), pp. 8065-8070

McCracken, M.W (1999), Asymptotics for out of Sample tests of Causality. Working Paper, Louisiana State University.

Newey, W.K. and K.D., West (1987), A simple positive semi-definite heteroskedasticity and autocorrelation consistent covariance matrix. Econometrica 55, 703-708.

Phillips, P.C.B., (1987), Time series regression with a unit root. Econometrica 55, $277-301$.

Porterba, J. M. and L. H., Summers (1988) Mean reversion in stock prices: evidence and implications, Journal of Financial Economics, 22, 27-59.

Robinson, P., (1995a), Log-periodogram regression of time series with long range dependence. The Annals of Statistics 23, 1048-1072.

(1995b), Gaussian semiparametric estimation of long range dependence. The Annals of Statistics 23, 1630-1661.

(2003), Time Series with Long-memory. Oxford University Press, Oxford. 
Shimotsu, K., P.C.B., Phillips (2002), Exact local Whittle estimation of fractional integration. Working Paper, University of Essex.

Sivakumar, P.B. , Mohandas, V. P. (2009). Modeling and Predicting Stock Returns using the ARFIMA-FIGARCH: A Case Study on Indian Stock data

Sowell, F.B., (1992), Modelling long-run behavior with the fractional ARIMA model. Journal of Monetary Economics 29, 277-302.

Taqqu, M., and V., Teverovsky (1997), Robustness of Whittle-type estimators for time series with long-range dependence. Stochastic Models 13, 723-757.

Tu, A. H., W.K., Wong and M.C., Chang (2008), Value-at Risk for Short and Long positions of Asian stock markets. International Research Journal of Finance and Economics, Issue 22, 135-143.

Vougas, D (2004), Analysing Long Memory and Volatility of Returns in the Athens Stock Exchange Applied Financial Economics, 14:457-460.

West, K. (1996), Asymptotic Inference about Predictive Ability. Econometrica 64, 1067-1084.

White, H (2000), A reality Check for Data snooping. Econometrica 68, 1097-1126.

Wright, J.H., (2001), Long-memory in emerging market stock returns. Emerging Markets Quarterly 5, 50-55.

Yoo, S. (2011), G-3 and BRICK Stock Markets: Co-integration and Its Forecasting Ability. Senior Honors Thesis, University of Michigan. 